\title{
The Trial Implementation of Emission Trading in China
}

\author{
Haolin Xu \\ 182 Nanhu Avenue, East Lake High-tech Development Zone, Wuhan 430073, Hubei Province, \\ China \\ angela@cas-harbour.org
}

Keywords: Emission trading, China, Feasibility.

\begin{abstract}
The emission trading system is a system which is being vigorously promoted by the country to solve the problem of enterprise emission. It worked well in the United States and other European countries, but more than ten years ago, this system failed when it was tried out in some provinces of China. This paper first listed the theoretical basis of emission rights trading, analyzed its feasibility, and then summarized the reasons for the failure of the previous trial through consulting materials. Through the analysis, the author finally gave some suggestions for promotion at the present stage.
\end{abstract}

\section{Introduction}

Chinese economy is in a complex stage. Since it is in the early stage of reform and opening up, there is no doubt that Chinese economic development has made remarkable achievements, which is closely related to the rapid development of Chinese industry and manufacturing industry. However, due to the low technical level of Chinese industry and manufacturing industry and extensive production mode, a large number of pollutants such as wastewater, waste gas, and waste residue are directly discharged into the environment before being treated to the standard, causing a nationwide environmental pollution problem. In more recent years. The frequent occurrence of haze weather around the country has led the public and the government to focus on environmental issues and realize the importance of environmental pollution. In this context, Chinese previous pilot emission trading system in large areas of Hunan and Hubei provinces, which can effectively deal with the problems caused by pollution externalities, is an attempt to allocate the responsibility of environmental pollution prevention and control through the market, but the effect is not ideal. Theoretically speaking, emission trading system can minimize the environmental problems caused by the unreasonable allocation of emission indicators and other reasons through market regulation, which is the only way to alleviate the contradiction between environmental pollution and economic development to a large extent. So, what factors caused the failure of the implementation of the emission trading system and how to promote it successfully are the questions that many scholars are studying now.

\section{Analysis on Emission Trading System}

\subsection{The Theoretical Basis of Emission Trading System}

There are two kinds of emission trading, namely pollutant trading, and carbon emission trading. Among them, carbon emission trading is a mainstream part of the world, but it has not been implemented in China. As early as 1987, emission right trading of pollutants was first tried in Shanghai ${ }^{[1]}$, which has a history of more than 30 years. Both emission rights trading theories are based on coase property rights theory, which endows environmental capacity with scarcity and value. Currently, haze, acid rain and other problems are serious in China, which are generally caused by excessive emission of pollutants. However, greenhouse gas emission is a global problem. In China, it causes less harm than the discharge of pollutants. As a result, China has an obvious bias towards different emission trading mechanisms. The trading of pollutant discharge right mainly implemented in China is the trading of quota difference, and the trading of enterprises in the market is the residual emission after meeting the requirements of their own emission after being determined by the government after accounting. This approach gives enterprises some flexibility, but it is not a complete 
environmental and economic policy ${ }^{[2]}$, and there are still some defects.

\subsection{Mathematical Model Analysis of Emission Trading System}

According to the coase theorem, when the transaction costs are zero, and the pollution control costs are different between market entities, emission trading will naturally

take place among enterprises due to supply and demand. The following is the economic analysis of micro individuals in emission rights trading based on mathematical model:

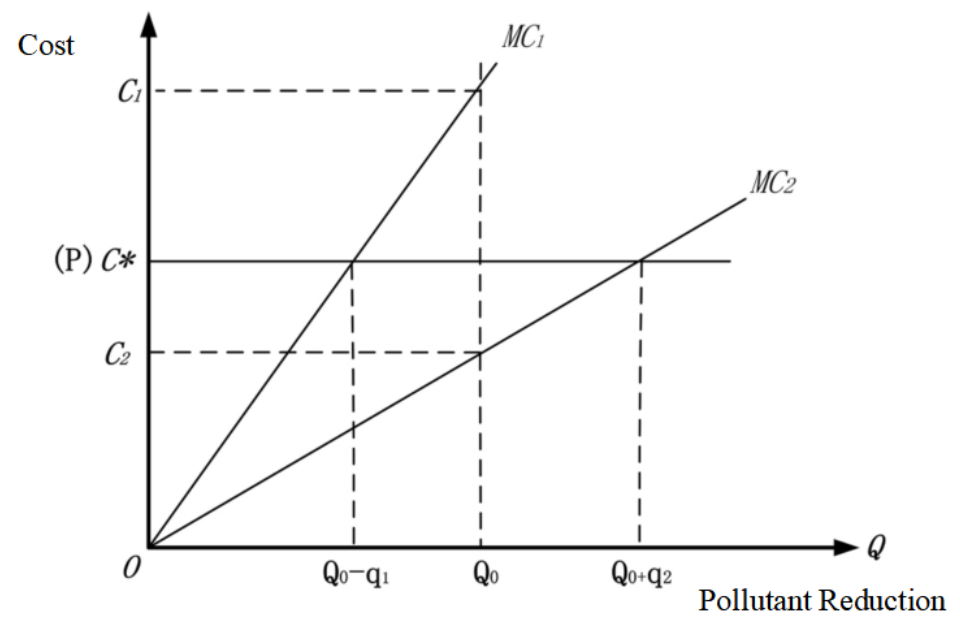

Fig. 1. The economics of emissions trading

Among them, the vertical coordinate represents the cost of pollution control, which can also be seen as the tradable price of emission rights, and the horizontal coordinate represents the established reduction amount of pollutants. $\mathrm{MC}_{1}$ and $\mathrm{MC}_{2}$ represent marginal pollution control costs of enterprise A and $B$ respectively. As shown in figure 1, the slope of the two marginal pollution control cost curves respectively represents the marginal pollution control cost of the two enterprises. Obviously, the cost of enterprise B is lower than that of enterprise A. It is assumed that the government rules every enterprise should have the amount of pollutant reduction $\mathrm{Q}_{0}$, then under the condition of the zero transaction cost, the two companies will spontaneously trade permits, allowing them to achieve marginal pollution control cost minimization, namely enterprise B will sell its pollution index after the rest of the $\mathrm{q}_{2}$ anti-pollution capacity. The marginal cost of controlling pollution due to high A cost by buying the amount of the pollution treatment in $\mathrm{q}_{1}$ has to meet the prescribed standards for pollution $\mathrm{Q}_{0}$, thus we have $\mathrm{q}_{1}=\mathrm{q}_{2}$. When the pollution treatment costs of two enterprises in the last unit are equal, the trading of emission rights will stop. At this point, the pollution treatment costs formed in the trading market are $C^{*}$, and the trading equilibrium price is $p$, so $p=C^{*}$. When the market allows trading of emission rights, the cost of pollution control for each enterprise consists of two parts. One part is its own pollution control cost $\mathrm{C}_{\mathrm{i}}(\mathrm{i}=1,2)$, and the other part is the market trading price $\mathrm{p}$ of emission right formed under the influence of supply and demand. The corresponding pollution control quantity that each enterprise buys or sells in the market is $q_{i}(i=1,2)$. Therefore, the total pollution control cost of both parties before the transaction is delta $1 / 2 \mathrm{ci}\left(\mathrm{Q}_{0} \pm \mathrm{q}_{\mathrm{i}}\right) \pm \mathrm{pq}$ irea, while the total pollution control cost after the transaction is delta $1 / 2 \mathrm{ci}\left(\mathrm{Q}_{0} \pm \mathrm{q}_{\mathrm{i}}\right) \pm \mathrm{pq} \mathrm{i}_{\mathrm{i}}$ area. It can be inferred that the total cost of social pollution control saved by enterprises after the transaction is

$$
\mathrm{Si}=1 / 2 \mathrm{CiQ0}-[1 / 2 \mathrm{C} *(\mathrm{Q} 0 \pm \mathrm{qi}) \pm \mathrm{pqi}]
$$

The cost saved by enterprise $\mathrm{A}$ through emission right exchange is as follows:

$$
\mathrm{SA}=\frac{1}{2} \mathrm{C} 1 \mathrm{Q} 0-\left[\frac{1}{2} \mathrm{C} *(\mathrm{Q} 0-\mathrm{q} 1)+\mathrm{pq} 1\right]=\frac{1}{2}(\mathrm{C} 1-\mathrm{C} *) \mathrm{q} 1
$$

The cost saved by enterprise $\mathrm{B}$ through emission right exchange is:

$$
\mathrm{SB}=\frac{1}{2} \mathrm{C} 2 \mathrm{Q} 0-\left[\frac{1}{2} \mathrm{C} *(\mathrm{Q} 0+\mathrm{q} 2)-\mathrm{pq} 2\right]=\frac{1}{2}(\mathrm{C} *-\mathrm{C} 2) \mathrm{q} 2
$$

The total cost saved by the two enterprises through the emission trading market is:

$$
\mathrm{TSAB}=\mathrm{SA}+\mathrm{SB}=1 / 2(\mathrm{C} 1 \mathrm{q} 1-\mathrm{C} 2 \mathrm{q} 2)
$$


To sum up, $1 / 2\left(\mathrm{C}_{1} \mathrm{q}_{1}-\mathrm{C}_{2} \mathrm{q}_{2}\right)$ is the total cost of pollution control saved by the two enterprises after the implementation of pollution rights trading. Through the analysis of micro model, it can be seen that allowing emission trading can not only reduce the cost of enterprises' established emission reduction targets, but also lead enterprises to carry out technological innovation to improve the efficiency of pollution control. From the perspective of the society as a whole, the marketization transfer of pollutant discharge right among enterprises is actually a process from polluters with high treatment cost to polluters with low treatment cost. As a result, the whole society will realize pollutant emission reduction at the lowest cost and environmental resources can be allocated efficiently ${ }^{[3]}$.

\section{Reasons for Failure of Emission Trading System in China}

So far, Chinese domestic emission trading has been tried out for more than ten years in Hubei and Hunan provinces, but the results are not optimistic. The reasons can be summarized as follows:

\subsection{An Imperfect Legal System}

From a legal perspective, there are two reasons for the failure. One is the legal attribute of sewage's discharge right is not clear, which means that there is no clear legal basis. The current law in China deficiencies exist in the aspect of environmental legislation and in other relevant prevention and control of environmental law under the premise of not perfect, is closely related with the emissions trading system which is also difficult to achieve the fairness and reasonability. In addition, different regions and cities have different market levels, which also cause difficulties for marketization of emission rights. The greater the difference between total emissions and market environment, the more difficult it is to coordinate. Second, the initial allocation and monitoring and review system is unreasonable. The trading process of emission rights includes the initial allocation of emission quotas among different enterprises and the monitoring and review of emission by relevant government units. Reasonable initial allocation is very important to ensure the enthusiasm of enterprises for emission trading and the credibility of the government. However, at present, the initial allocation of most pilot areas in China is not reasonable. At the same time, the imperfect monitoring and review system makes many enterprises in pilot areas use emission trading system in pursuit of higher economic interests, resulting in greater environmental pollution, which is contrary to the purpose of the emission trading system ${ }^{[4]}$.

\subsection{Multiple Ways to Reduce Emissions}

Due to the country and the urgent demand for environmental quality, the government has issued a series of strict emission reduction targets and implemented many of the administrative and economic measures, such as in order to realize "APEC meeting" blue sky in previous years, the government promulgated "one size fits all" policy that focused on the closure of small and medium-sized enterprise pollution production, which led to the total emission of pollutants discharge less than usual days in a short time, thus effectively solved the problems of atmospheric pollution in Beijing. But to a great extent, it also squeezed the emission permits market space and will not form the system of emissions trading in the cradle or help promote the system. Thermal power is the first big power source in our country at present, as the country in recent years issued a variety of mandatory emission reduction efforts to reduce emissions and outdated technology, companies use the same means of reduction, purchasing similar facilities to reduce emissions, there is no difference between each other huge unit emissions, so it is hard to exist emission difference, do not need to get permits by trading means.

\subsection{Non-constant Total Discharge}

Total quantity control is the premise of emission trading system. Total quantity control is to determine the maximum amount of pollutants discharged in an ecological function area, and implement measures to control the pollutant discharge within the total amount, so as to ensure that the ecological environment quality of the area meets the requirements of people's life. At present, it is a big problem to determine and coordinate the total amount of each region and the total amount of the whole country. 
The ecological environment protection system in China is mainly implemented by different regions according to the administrative divisions. It is difficult to control the total amount of each administrative division at the same time. However, there is no administrative boundary in the ecological environment area. For example, a river usually flows through many provinces. If the upstream area continues to discharge sewage, the effect of implementing total volume control and paid use and trading of emission rights in the downstream area is actually equal to zero due to the influence of pollutants in the upstream. Therefore, the inconsistencies between the man-made administrative regional planning and the natural ecological environment regions are also one of the important reasons that hinder the total emission determination and the implementation of the emission right trading system.

\subsection{General Pollution Monitoring Problem}

High technical support and equipment support are also necessary conditions for the implementation of emission trading system, among which ecological environment monitoring is an important technical guarantee. At present, although China's environmental monitoring equipment is simple, backward technology, lack of unified monitoring system and standards, most cases are selected by the relevant departments, it is difficult to conduct continuous monitoring of an ecological functional area, in order to obtain effective real-time data. In the meantime, if the enterprise does not undertake declaring, the discharge of contaminant below most circumstance did not get effective supervisory control, the enterprise can choose privately blowdown and do not choose to buy blowdown authority. In order to obtain effective real-time data, it is necessary to purchase and introduce a large number of advanced detection equipment, which is an additional cost to purchase, operate and maintain, hindering the further implementation of emission trading.

\section{Suggestions}

\subsection{Establish Regional Emission Trading Markets}

The smooth operation of the emission trading market requires a certain scale of trading areas and management objects to ensure the number of suppliers and demanders in the market. However, at present, China's emission trading is only piloted in the province, trading within cities or counties at all levels, as cross-regional trading is difficult and unable to form a large-scale trading market. And because the natural ecological environment of the area often do not coincide with administrative areas, it is difficult to complete it within the same province of well-coordinated trading market, according to the division of multiple regions in different parts of the natural environment, or an area to set up their own emission trading market and better natural environment adapted to the market rules.

\subsection{Improve Relevant Legal Systems}

Clarify the legal attribute of the right to discharge pollutants, so that the right to discharge pollutants can be confirmed by law. At present, emission right trading should be the right of possessor of emission right to possess, use, profit and dispose of. The system of environmental resource property right can be confirmed through national legislation, and the legal status of emission right trading can be established, especially for the laws and technical specifications related to total quantity control, and specific operating rules can be formulated by corresponding local governments or environmental protection departments ${ }^{[5]}$.

\subsection{Promote Environmental Awareness among Citizens}

Setting up the concept of environmental protection for the whole people and forming an atmosphere of supervision and accountability for polluting enterprises can create a good and lasting external environment for emission trading. The government should publicize the importance of environmental value to polluters, cultivate their sense of social responsibility, and set up the concept of paying for environmental resources. 


\subsection{Accelerating Technological Progress}

Emission trading system requires monitoring technology must meet the requirements. China's current monitoring level is still low, the technology is backward, the equipment is old, thus there is a need to introduce advanced monitoring technology from abroad, establish scientific and accurate monitoring system, to ensure the smooth implementation of the emission trading system.

\section{Conclusion}

Generally speaking, emission trading is still in the development stage in China, and various regulations are not perfect temporarily. In order to ensure that relevant enterprises and companies can enjoy a fair and just environment in emission trading, relevant professionals must set out from the reality, formulate effective rules and regulations, try to ensure the integrity and perfection of emission trading institutions, and conduct emission trading process Standardization of methods, institutionalization of operation, etc. While promoting the sustainable and healthy development of economy, emission trading plays an important role in the social ecological environment and the environment of people to people and cultural exchanges, and truly achieves the economic concept of green development and sustainable development.

\section{Acknowledgement}

First and foremost, I would like to show my deepest gratitude to my teachers and professors in my university, who have provided me with valuable guidance in every stage of the writing of this thesis. Further, I would like to thank all my friends and roommates for their encouragement and support. Without all their enlightening instruction and impressive kindness, I could not have completed my thesis.

\section{References}

[1] B. J. Liu, Vigorously promote pilot emission trading to create innovative situation of emission reduction work [J], Environmental protection, vol.18, pp.22-25,2014.

[2] Z. X. Wu, S. A. Zeng, Establishment of emission trading mechanism under the unified framework of China [J], Journal of humanities, vol. 8, pp.62-69, 2008.

[3] M. B. Xu, Y. N. Zhang, Analysis on constraints and role of government in emission trading system [J], Journal of yanbian university, vol. 51,pp.108-116,2008.

[4] Z. Y. Meng, Research on legal issues of emission rights trading [J], Legal expo, vol. 31, pp.116$117,2008$.

[5] R. L. Jin, Environmental Law [M]. Beijing: Peking University press, pp.87-90,2016. 